\title{
OS DIREITOS SOCIAIS ENQUANTO DIREITOS FUNDAMENTAIS
}

\author{
Marcus Orione Gonçalves Correia \\ Professor Associado do Departamento de Direito \\ do Trabalho da Faculdade de Direito da \\ Universidade de São Paulo.
}

Resumo:

Busca-se comprovar a relevância da interpretação constitucional na consolidação dos direitos sociais. A partir do enquadramento destes dentre os direitos fundamentais, pretende-se demonstrar a necessidade de uma metodologia de interpretação essencialmente baseada nos principios, com relevo para o princípio da dignidade humana.

Abstract:

One searches to prove the relevance of the constitutional interpretation in the consolidation of the social rights. From the framing of these amongst the basic rights, it is intended to demonstrate the necessity of a methodology of interpretation essentially based in the principles, with relief for the principle of the human being dignity.

Unitermos: interpretação constitucional; Direitos Sociais; princípio da dignidade humana.

Keywords: constitutional interpretation; Rights Social; human being dignity.

I. Introdução: o posicionamento estratégico dos direitos sociais no contexto constitucional

A abordagem do presente tema é tarefa impostergável, na medida em que se faz urgente a consolidação da leitura de efetivação dos direitos sociais (com lugar de destaque para os direitos previdenciários) enquanto direitos fundamentais.

Tentaremos, portanto, exibir e resolver algumas das mais intrigantes questões referentes à matéria, fazendo uma análise tendente à otimização dos direitos sociais, a partir da metodologia de interpretação constitucional.

Já de início urge frisar que a simples constatação dos direitos sociais como direitos fundamentais, por si só, provoca, em alguns poucos, perplexidade que deve ser afastada, já que decorre da própria evolução dos direitos sociais. 
Na perspectiva, abandonada por muitos, das gerações dos direitos, esta modalidade jurídica se encontraria dentre aquelas de segunda geração. Seguiriam aos de primeira geração, de indole essencialmente liberal, isto é, as liberdades públicas. Seriam, por outro lado, antecessores dos direitos de solidariedade, ligados a interesses como, v.g., a paz no plano internacional, também conhecidos como terceira geração.

Esta teoria da geração dos diruitos, no entanto, tem sido bastante combatida, sob a alegação, que entendemos pertinente, de que não há que se ter como estanques os diversos direitos antes elencados. 'Assim, para o devido entendimento dos direitos sociais faz-se indispensável a compreensão $\mathrm{c}$, mesmo a utilização, de instrumentais relacionados com os direitos individuais. Por seu turno, os direitos de solidariedade também se revelam indispensáveis ao conhecimento dos direitos sociais aliás, não há como se esconder a relação do princípio da solidariedade, reitor do direito previdenciário, com a idéia que permeia a construção e consolidação dos direitos chamados de terceira geração, também conhecidos como

1. Devem ser destacadas, neste item, as seguintes objeções postas por CANÇADO TRINDADF no "Seminário Direitos Humanos das Mulheres: a proteção internacional", evento associado à V Conferência Nacional de Direitos Humanos, realizado no dia 25 de maio de 2000, na ('âmara dos Deputados Federais, Brasilia, DF: "Eu não aceito de forma alguma a concepção de Norberto Bobbio das teorias do Direito. Primeiro, porque não são dele. Quem formulou a tese das geraçũes de direito foi - Karel Vasak, em conferência ministrada em 1979, no Instituto Internacional de Direitos Humanos, em Estrasburgo (...) Em primeiro, essa tese das gerações de direitos não tem nenhum fundamento juridico, nem na realidade. Essa teoria é fragmentadora, atomista e toma os direitos de maneira absolutamente dividida. (...) Essa conceituação de que primeiro vieram os direitos individuais e, nesta ordem, os dircitos econômico-sociais e o direito da coletividade correspondem à evoluçâo do direito constitucional. É verdade que isso ocorreu no plano dos direitos internos dos paises, mas no plano internacional a ıvoluçăo foi contrária. No plano internacional, os direitos que apareceram primeiro foram os econômicos e sociais. (...) Segundo, é uma construção perigosa, porque faz analogia com o conceito de gerações. O referido conceito se refere praticamente a gerações de seres humanos que se sucedem no tempo. Desaparece uma geração. vem outra geração c assim sucessivamente. Na minha concepção, quando surge um novo direito, os direitos anteriores não desaparecem. Há um processo de cumulação e de expansão do 'corpus iuris' dos direitos humanos. Os direitos se ampliam, e os novos direitos enriquecem os direitos anteriores" Mais adiante o autor assevera que esta divisão tem "causado grande dano à uvolução dos direitos", dizendo que embora, v.g., não se tolere a discriminação no plano dos direitos civis e políticos, esta vem sendo tolerada em relação aos direitos sociais. econômicos e sociais, apenas pela razão destes últimos pertencerem à segunda geração è serem de realização progressiva. Diante disto, preleciona que: "Então, vemos uma condenação absoluta de qualquer tipo de discriminação quando se trata de direito individual ou mesmo de direitos politicos, mas uma tolerância absoluta quando se trata de disparidades em matéria de salário, renda, e assim por diante. Em vez de ajudar a combater essa visão atomizada, essa teoria de geração de dircitos convalida esse tipo de disparidades" 
direitos de solidariedade. ${ }^{2}$ Por outro lado, a própria expressão geração de direitos é bastante imprópria, dando a sugerir a exclusão de postulados de uma das gerações na consolidação dos conceitos envolvendo os de outras. Aliás, um exemplo prático da dificuldade criada por esta classificação refere-se à própria idéia inculcada a partir das gerações da imediata relação apenas entre os direitos de solidariedade e os interesses difusos. $\mathrm{Na}$ verdade, embora os chamados de terceira geração efetivamente se situem no plano difuso, isto não quer dizer que o mesmo não se dê com os direitos sociais, por exemplo, (embora estes também possam ter exercício na esfera individual, na essência, devem ser entendidos de forma também difusa). ${ }^{3}$

Ressalte-se, ainda, que, sob as perspectivas dos direitos fundamentais da pessoa humana, os direitos sociais foram destacados, no nosso contexto, para o Título II do texto constitucional, que se refere exatamente aos direitos e garantias fundamentais. A despeito da impossibilidade, admitida pela doutrina e jurisprudência em geral (incluída aqui a do Supremo Tribunal Federal), de hierarquização das normas constitucionais, não há como se esconder, especialmente em vista das cláusulas pétreas do art. $60, \S 4^{\circ}$, da Constituição Federal, que esta disposição dos direitos sociais em sede constitucional. no presente sistema, é bastante útil e, no nosso sentir, inviabilizadora inclusive de reduções dos direitos

2. Aliás, nunca é demais lembrar que o princípio da solidariedade do direito da segurança social deve ser analisado, enquanto principio explícito, como decorrente não apenas da expressão constante do art. 195 da Constituição Federal (solidariedade no custeio), mas também do art. 3o, inciso I, do texto constitucional (que induz à possibilidade da introdução da idéia de solidariedade também no momento da distribuição dos beneficios). Aliás, urge constatar que um dos objetivos fundamentais da República Federativa do Brasil refere-se à construção de uma sociedade solidária, sendo correlato à idéia de que no plano internacional as relações entre as nações deve se pautar na solidariedade.

3. Embora possam ser gozados na dimensão individual. enquanto patrimônio jurídico caro a toda a sociedade, os direitos fundamentais devem ter a sua defesa potencializada na usfera coletiva. Ora, 0 direito à vida, à locomoção, ao trabalho, como tantos outros arrolados no art. 5o., da ('onstituição Fideral, merecem atenção e tutela especialmente coletiva. O tratamento coletivo, para a tutela dos direitos humanos, revela o próprio cuidado que se tem com os mais caros interesses a serem resguardados perante a ordem juridica. Logo, sendo na sua essência difusos, us direitos fundamentais tìm na tutela coletiva uma de suas mais eficientes armas. E mais: isto se dá, inclusive e especialmente, com os direitos sociais (como o direito ao trabalho, à previdência social e à saúde). Estes são, na sua cssência. difusos. Embora possam ser gozados na dimensão individual, estes direitos são essencialmente difusos - mesmo porque ligados, ainda que indiretamente, à idéia que pauta a formação dos direitos de terceira geração, forjados na idéia de solidariedade. 
sociais apostos constitucionalmente. ${ }^{4}$ Da mesma forma, a utilização destes direitos como fundamentais viabiliza a maior efetividade da sua tutela, inclusive no plano da tutela coletiva e da participação de entidades associativas e do Ministério Público em sua defesa.

Diga-se, ainda, que não há qualquer novidade neste reposicionamento dos direitos sociais, já que se trata de uma natural evolução do "status" conferido a estes. A verdade é que os direitos fundamentais deixaram de ser concebidos apenas a partir da perspectiva das liberdades públicas - em que se buscava do Fstado apenas uma postura passiva. Os direitos fundamentais da pessoa humana devem ser concebidos, portanto, não apenas a partir da perspectiva individual, mas também à luz dos direitos sociais. Aliás, não há como se conceber a consolidação destes direitos fundamentais apenas da perspectiva do indivíduo isoladamente considerado, mas também a partir de sua inserção na coletividade. Aliás, temos constantemente afirmado que esta nova visâo dos direitos fundamentais, com uma perspectiva mais social, é sentida de forma bem comum a partir da idéia de que o próprio

4. Neste compasso, KONRAD HFSSE já vislumbrou a existência de um principio do estado social, asseverando que "se todas essas obrigações sociais carecem também de concretização e realização pela legislação ordinária, freqüentemente também pelo tornar-se ativo administrativo. o principio do estado social permanece, contudo, um principio constitucional: ele obriga e legitima o legislador e o poder executivo para o exercício de tarefas estatal-sociais" (Elementos de Direito Constitucional da República Federal da Alemanha. (Tradução Luis Afonso Heck) Porto Alegre : Sérgio Antônio Fabris Fditor, 1998, p. 175). Já para J. J. GOMES CANOTILHO merece destaque o principio do não retrocesso social, frisando que a idéia expressa a partir deste "tem sido designada como proibição de 'contra-revolução social' ou de 'evolução reaccionária' Com isto quer dizer-se que os direitos sociais e económicos (ex: direitos dos trabalhadores, direito à assistência, direito à educação), uma vez obtido um determinado grau de realização, passam a constituir, simultaneamente, uma garantia institucional e um direito subjectivo" (Direito Constitucional e Teoria da Constituição. Coimbra : Livraria Almedina, 1998, p. 320).

Logo, não há como se desprezar o papel estratégico dos direitos sociais nas constituições modemas, o que, inclusive, chega a contrastar com o fenômeno da propagada diminuição de direitos trabalhistas e previdenciários. muito em voga ultimamente no nosso pais. Esta noção conspira contra leitura que temos feito do direito adquirido social que inviabiliza a modificação de direitos fundamentais incorporados, enquanto evolução do direito. ao patrimônio jurídico de uma sociedade. 
constitucionalismo teria sofrido profundo impacto das Constituições mexicana, de 1917, e de Weimar, de $1919^{5}$

II. Os direitos sociais como direitos fundamentais - inviabilidade de atuação supressiva do poder constituinte derivado

Deve-se ressaltar, inicialmente, que há sistemas constitucionais em que há maior facilidade para a reforma constitucional e aqueles que tratam o regime de competências para a reforma da Constituição de forma mais rigorosa.

Adentramos, aqui, na questão das reformas do texto constitucional, e mais especificamente, no campo de atuação do poder constituinte derivado. A despeito de honrosas posições em contrário. entendemos este como poder jurídico (e não mero poder de fato) limitado pela atuação e obra do poder constituinte originário. Estas limitações, por sua vez, podem ser expressas e implicitas (em torno das quais não há consenso, a despeito da posição já adotada em alguns julgados, no sentido de sua admissão. pelo Supremo Tribunal Federal e do entendimento de ilustres juristas como Canotilho. Harriou e José Afonso da Silva).

Interessam-nos, inobstante, as limitações expressas, que podem ser formais ou circunstanciais. Há, no ordenamento pátrio, que se considerar também

5. A leitura da Constituição mexicana revela um modelo bastante minucioso quanto ao elenco dos dircitos sociais. fazendo constar desde o direito a horas extras até questões como o trabalho noturno. Deve-se inclusive ver que a pormenorização dos direitos dos trabalhadores, e em menor grau dos direitos previdenciários, lembra bastante a nossa atual Constituição Federal. especialmente em seu art. $7^{\circ}$. Já a Constituição de Weimar de 1919 é menos descritiva dos direitos dos trabalhadores, contendo apenas os postulados que iriam pautar o modelo trabalhista no plano infraconstitucional. Assim. por exemplo, a partir da Constituição de Weimar, verificou-se verdadeira modificação no modelo juslaboralista, como se observa das seguinte observações. Inicialmente colhe registrar a passagem do modelo repressivo sindical de Bismarck (em que os direitos sociais eram concedidos em contrapartida à renúncia da participação coletiva - sindical), para um modelo de tolerância e, por fim já em Weimar, um modelo de permissão. Por outro lado, antes de Weimar, o Direito do Trabalho tedesco fazia parte do Direito Civil (locação de serviços). Estávamos diante de um contrato individual que se incorporava à lógica privada. Com Weimar, abre-se caminho para a autonomia do Direito do Trabalho, inclusive com passagem do Direito privado para o Dircito Constitucional (e com uma estrutura próprio até mesmo para o julgamento dos feitos). Com Weimar, começa a existir um direito do trabalho protetor do trabalhador (limitação de jornada de trabalho, criação de um justiça especializada e colocação pública de mão-de-obra, por exemplo). Estavam assentadas as bases para a autonomia do Direito do Trabalho: defesa dos trabalhadores e coletivismo. No entanto. não se deve deixar de reconhecer que a República de Weimar, na sua estrutura constitucional e infraconstitucional de direito do trabalho, teria lançado o sustentáculo para um modelo que impregnaria a ideologia facista ("antes de tudo em Weimar", conforme a frase de FRANZ NEUMANN). 
como expressa a limitação de atuação do poder constituinte derivado nos casos elencados no art. $60, \S 4^{\circ}$, da Constituição Federal.

Assim, no nosso caso, dotou-se o sistema de uma certa rigidez, inviabilizando que a competência fosse dada ao legislador constituinte derivado em algumas situações previstas no próprio corpo da ('onstituição. Trata-se das cláusulas pétreas.

Embora venha sendo difícil o estabelecimento de uma hierarquia das normas constitucionais com a gradação de normas constitucionais mais ou menos relevantes -, não hả como se esconder o fato de que em relação às situações do art. $60, \S 4^{\circ}$ da Constituição, a competência estabelecida apenas em favor do legislador constituinte originário revela o cuidado com a reforma das matérias ali elencadas. Ressalte-se que não estamos, neste ponto, defendendo a existência de normas constitucionais inconstitucionais ou mesmo de hicrarquia entre as normas constitucionais, o que inclusive é rechaçado pela doutrina pátria e pelo Colendo Supremo Tribunal Federal. Aliás, esta construção seria inviável dentre um sistema de interpretação baseado especialmente no cotejo de principios, em que estes não se subınetem a uma disposição hierárquica, já que não estão submetidos - como as regras à idéia de "tudo ou nada" Os princípios devem ser sopesados diante das situações concretas, havendo ora a superposição de um em relação ao outro c ora o contrário.

Assim, no nosso Estado, não pode ser objeto de aluação do legislador constituinte derivado proposta tendente à abolição:

a) a forma federativa de Estado,

b) o voto direto, secreto, universal e periódico,

c) a separação dos Poderes,

d) os direitos e garantias individuais.

Percuba-se que, pelo artigo $60, \S 4^{\circ}$ do texto constitucional, proposta de Emenda Constitucional, tendente a abolir quaisquer um dos itens acima. não deverá ser acolhida. Basta que a proposta indique uma tendência à abolição de qualquer uma das matérias anteriores para que seja refutada. Não é necessária a abolição imediata, sendo suficiente a mera ameaça de abolição.

No nosso caso, interessa a verificação do real conteúdo da abrangência da inviabilidade de modificação, por ato do constituinte derivado, dos direitos fundamentais da pessoa humana. 
Do que se tratam estes direitos e garantias individuais? Dentre eles se incluem os direitos sociais?

A questão não é simples. No entanto, ousamos enfrentá-la a partir de algumas premissas, a saber:

a) a interpretação não pode ser meramente literal. Afinal, se assim o fosse, sequer seria possivel dizer que as situaçðes do próprio art. $5^{\circ} \mathrm{em}$ sua inteireza ıstariam infensas à atuação do poder constituinte derivado. Ora, da simples leitura do Título em que se insere este dispositivo a insuficiência seria imediatamente revelada, já que aquele (Título II) refere-se aos direitos e garantias fundamentais (e não apenas aos direitos e garantias individuais). Já o Capítulo I deste Título se refere de forma mais ampla aos direitos e deveres individuais e coletivos. Ora, a se considerar que apenas os dircitos fundamentais individuais se encontrariam abrangidos, outros que podem ser analisados pelo viés individual, mas também coletivo, não estariam (como é o caso do direito de associação, que é individual, quando visto sob a perspectiva da liberdade de ingresso, mas é coletivo, quando visto da perspectiva da entidade já constituída, a que se deve preservar para que o próprio interesse individual fique ileso). Portanto, seria pouco provável a interpretação meramente literal.

b) a interpretação deve ser, portanto, teleológica e sistemática. Os valores apostos nos princípios fundamentais do Título I invocam a idéia de que há que se valorizar não apenas o individuo para a formação do Estado Democrático de Direito, que é fundamento da República Federativa do Brasil. Assim, valores sociais também são fundamentais para o nosso modelo (como os valores sociais do trabalho e da livre iniciativa e, mesmo a cidadania do art. $1^{\circ}$, inciso I, que não é valor apenas individual, mas tambím social). Logo, sendo os dircitos sociais direitos fundamentais do Título II, eles devem ser tidos na mesma dimensão dos direitos individuais, inclusive quanto às restrições que se possam fazer à atuação do poder constituinte derivado.

c) a própria evolução histórica dos direitos sociais, já declinada anteriormente, thes confere "status" semelhante aos direitos individuais, quanto à extensão inclusive de restrições para a sua retirada do ordenamento constitucional. Aliás, considerar de forma difurente seria dar, o que não admite o próprio Supremo Tribunal Federal, hierarquia distinta e menos importante aos direitos sociais, quando cotejados com os dircitos individuais enquanto direitos fundamentais. Assim, 
existiriam alguns direitos fundamentais que seriam menos fundamentais do que os outros e, portanto, poderiam ser mais facilmente removidos do sistema constitucional, por atuação do poder constituinte derivado. Istu remonta a construções de natureza liberal. que não mais devem permear a leitura dos direitos e garantias fundamentais, mesmo porque não constituem os postulados máximos e únicos da atual Constituição da República.

d) devem ser entendidos como fundamentais não apenas os direitos sociais dos arts. 6o. a 11 da Constituição Federal, mas todos aqueles que permeiam a Constituição Federal e sem os quais os direitos sociais não resistiriam na vida cotidiana. Aliás, esta interpretação exsurge da própria leitura feita pelo Supremo Tribunal Federal, da ADIN 939, relatada pelo ministro Sidney Sanches, que entendeu que os direitos individuais a serem preservados como cláusulas pétreas não são apenas os elencados no art. $5^{\circ}$ da Constituição Federal, mas outros espalhados pela Constituição que the garantam efetividade (como, por exemplo, o art. 150, inciso VI, "a", "b", "c" e "d" da Constituição). Ora, entende-se que este mesmo raciocínio possa ser estendido aos direitos sociais. Senão vejamos. O direito à previdência social, com a preservação de todos os seus beneficios e de corolários que são indispensáveis à concretização destes benefícios (como, por exemplo, a devida preservação do seu valor real e a correção dos salários-de-contribuição), encontra-se dentre os direitos fundamentais da pessoa humana. Embora apenas o art. $6^{\circ}$ (que menciona como direito social também a previdência) esteja situado no título II da Constituição Federal, não há como se deixar de atribuir a mesma natureza de direito fundamental do homem a dispositivos constantes dos arts. 194, 201 e 202 da Carta Magna. Ora, o direito à previdência é resguardado pela observância dos princípios e regras mínimos que the são inerentes (ou núcleo do direito, como pretendeu Robert Alexy em sua excelente obra Teoría de los derechos fundamentales. Madrid : Centro de Estudios Políticos e Constitucionales, 2001), que se encontram em parte distinta, mas são componentes básicos do direito à previdência social. Trata-se dos direitos fundamentais adstritos (ou materialmente fundamentais). Ora, de que adiantaria o direito fundamental à previdência social se não fosse observado o princípio, também constitucional, de preservação de valor real dos benefícios e a regra de correção dos salários-de-contribuição? Na verdade, para que o direito fundamental da pessoa humana seja efetivo. é inevitável que sejam observados todos os princípios e regras constitucionais que the garantam 
efetividade. Caso contrário, teríamos indesejável relativização dos direitos fundamentais.

Assim, na realidade, os direitos sociais devem ser tidos como fundamentais, com todas as conseqüências dai oriundas, isto é, até mesmo para efeitos da impossibilidade de sua supressão (ou da mera ameaça à supressão) por meio de Emenda Constitucional. É claro que esta ilação poderá levar à conclusão, que entendemos correta, de que as Emendas Constitucionais nos. 20/98 (em vários pontos $)^{6}$ e, em especial, a $41 / 98$ (em sua totalidade) ${ }^{7}$ conspiram contra cláusulas pétreas seja por atentados a direitos individuais, seja por violações a direitos sociais.

III. Os direitos sociais - mais do que mero programa, gerando direitos subjetivos

Muito se tem dito a respeito da implementação dos direitos sociais em geral. Aliás, na esfera da segurança social, a hipótese mais comum refere-sè à saúde. No entanto, ainda que $\mathrm{cm}$ menor grau (dado a maior especificação constitucional dos direitos previdenciários), a matéria também pode interessar à previdência social.

A idẽia de que os direitos de segunda geração (expressão que deve ser vista com reservas, como já mencionado) estariam essencialmente insculpidos em

6. A respcito confiram-se, por exemplo. as observações que já faziamos na obra Teoria e prática do poder de ação na defesa dos direitos sociais. São Paulo : LTr, 2002, p. 37, a respeito da inconstitucionalidade das regras de transição previstas na Emenda 20/98: "Na realidade, a inconstitucionalidade decorre de a emenda haver ferido 'cláusula pétrea' (art. 60, $\S 4^{\circ}$., da CF/88, segundo a qual 'não será objeto de deliberação a proposta de emenda tendente a abolir os direitos e garantias individuais'). Assim ocorre, na medida em que conspira contra a noção de direito adquirido antes explanada. Portanto, a disposição em comento atenta contra o que reza 0 art. 5o., inciso XXXVI. da Constituição Federal, exatamente inscrito dentre os direitos fundamentais. Do mesmo modo, a regra de transição fere o princípio da igualdade inscrito no 'caput' do art. 5o. da Constituição Federal. Se analisarmos a forma como se deu o aproveitamento do antigo sistema à lu $z$ do novo. percebe-se defasagem prejudicial a alguns segurados, em especial aos que tinham pouco tempo de serviço no antigo regime de aposentação". Perceba-se que, embora aqui a questão não seja da própria consideração da abolição (ou tendência à aboliçăo) do direito social, mas de direitos tipicamente tidos como individuais, não há como se desconsiderar a importância da observação. Assim, podem cxistir emendas cujo atentado se dê imediatamente contra o direito social (como no caso, um sua totalidade, da Emenda 4I/91) e uutras que o fazem de forma mediata. No caso antes mencionado, há primeiro o atentado a um dircito inicialmente vislumbrado apenas sob a perspectiva individual (o direito adquirido), mas que também poderia ser considerado sob o viés social.

7. A respeito confira-se o nosso artigo A reforma da previdência social c os survidores públicos que ingressaram no serviço público em data anterior à da publicação da emenda constitucional $n$. 41/03. Revista LTr, São Paulo, n. 279, fev. 2004, pp. 121-130. 
normas programáticas deve ser avaliada com muita cautela, por conta mesmo dos excessos e dificuldades que este raciocínio pode criar. Assim, os direitos sociais seriam aqueles que demandariam do Estado uma atitude ativa. para que todos pudessem usufruí-los. Nesta linha de raciocínio, a partir dos programas estabelecidos constitucionalmente. as políticas públicas deveriam observar as prioridades já postas anteriormente na Constituição. Esta idéia geralmente vem vinculada a outra de que, para a consecução dos direitos sociais, seriam exigidos gastos excessivos do Estado (afinal, ao direito à educação corresponde a necessidade de se criar um aparato para a sua concretização - construção de escolas, contratação de Professores, etc. , o mesmo se dando com o direito à saúde - edificação de hospitais, compra de medicamentos, contratação de médicos, etc.). Daí a dificuldade que muitos antevêem no suporte fático para a realização destes direitos, quase que os tendo como meras promessas adiadas sine die. ${ }^{8}$ Esta objeção. no entanto, não deve ser feita sem a avaliação também dos custos da manutenção das demais gerações de direitos (apenas para usar a expressão já consolidada por muitos na consciência jurídica). Ora, não há como se dizer que não haja a necessidade de programas e mesmo de gastos para a implementação dos direitos individuais (primeira geração). Ora, para que eu tenha a minha liberdade individual garantida, é necessário, por exemplo, que o Estado ponha à disposição todo o sistema de repressão - inclusive penal se for necessário -. decorrente da sanção, imposta pela norma. a yuem atente contra esta minha liberdade. Assim, a segurança pública é um exemplo de gasto geralmente ligado à proteção dos direitos individuais. O mesmo raciocínio poderia se dar com o ditos direitos de terceira geração. Ora, como se garantir a paz internacional sem gastos com embaixadas, com despesas para os envolvidos com a

8. Vale lembrar aqui as lições de Norberto Bobbio, segundo as quais: "Tanto é assim que, na Constituição italiana, as normas que se referem a direitos sociais foram chamadas pudicamente de 'programáticas' Será que já nos perguntamos alguma vez que gènero de normas são essas que nào ordenam, proíbem ou permitem hic et nunc. mas ordenam, proíbem e permitem num futuro indefinido e sem um prazo de carência claramente delimitado? E. sobretudo. já nos perguntamos alguma vez que gênero de direitos são esses que tais normas definem? Um direito cujo reconhecimento e cuja efetiva proteção são adiados sine die, além de confinadus à vontade de sujeitos cuja obrigação de executar o 'programa' é apenas uma obrigação moral ou, no máximo, política. pode ainda ser chamado corretamente de 'direito"? (A era dos direitos. Rio de Janeiro : Ed. Campus, p. 77 e 78). 
realização dos acordos internacionais ou com a manutenção de representações junto às organizações internacionais.'

Este equívoco deve ser desfeito, para que os gastos com os dircitos sociais não sejam tidos como óbices à implementação em especial das normas constitucionais que os garantam.

Por outro lado, há um problema criado pela idéia da existência de normas que seriam meramente programáticas.

Em sintese, esta modalidade de norma seria aquela que enunciaria um programa, dirigindo-se ao legislador para a sua implementação já que trata de politica pública, que deve ser disposta na legislação e, depois, implementada pelo executivo, observados critérios de oportunidade e conveniência. De imediato, já é possivel perceber-se que estas normas geram, com certeza e sem qualquer contestação pelos autores, direitos subjetivos negativos isto é, não seria possivel quer ao legislativo, quer ao executivo, ao executar programas previstos constitucionalmente, atuar de forma contrária aos postulados ali dispostos. A razão disto é relativamente simples, ao estabelecer, ainda que de forma genérica os seus propósitos, há uma vinculação dos diversos agentes políticos com os fins que a própria ('onstituição impôs e que vem retratado nos programas nela eleitos.

No entanto, tendo como destinatário o legislador, alguns entendem que estas não geram direitos subjetivos - o que refutamos, como se verá a seguir.

Deve-se entender, primeiro, que a idéia de norma programática vem muito difundida e associada à noção de Constituições dirigentes - consideradas aqui a partir de um conceito original do dirigismo para o socialismo. Em sua proposta tendente a um modelo socializante, os programas sociais já viriam insculpidos constitucionalmente - que seria uma Constituição que abre espaço para um futuro regime socialista (onde planificação plurianual e planejamento social detalhado são constantes ideológicas). ${ }^{10}$ Uma segunda concepção seria a mera colocação em sede

9. A respeitu confiram-se. neste sentido, os seguintes trechos de John Rawls. um liberal. que podem ser considerados no que concerne aos custos das liberdades: "Quando montam um tal sistema de sanções, as partes de uma convenção constituinte devem ponderar suas desvantagens. Fssas são no mínimo de duas espécies: uma espécie é a necessidade de cobrir os custos da manutenção do organismo, por exemplo, por meio de impostos (...) “ (In Uma teoria da justiça. São Paulo: Martins Fontes, 2000, p. 263).

10. CANOTILHO, José Joaquim Gomes. Constiluição dirigente e vinculação do legislador contributo para a compreensão das normas constitucionais programáticas. (2.ed.) Coimbra: Coimbra Editora. 2001. 
constitucional de normas programáticas e planificadoras, dirigidas ao Estado e a todos da sociedade, para a realização de uma nova ordem, ainda que não tendente à formação de um estado socialista.

Portanto, nestas Constituições - e muitos têm a Constituição brasileira de 1988 neste contexto, " embora partindo do último entendimento de Constituição dirigente -, é comum colocar que tal direito social será regulamentado observados os termos da lei. Isto é do estabelecimento de programas sociais, que ficam postergados para a futura atuação do legislador infraconstitucional.

Esta é uma questão de extrema importância para os direitos sociais em geral, e para os direitos previdenciários em particular e vai desembocar na questão da própria busca da tutela jurisdicional das normas programáticas.

Iniciamos, indagando: como, dentro de um contexto de direitos sociais, se entender a famosa expressão "nos termos da lei" em que geralmente se encontra envolto o programa constitucional?

Por exemplo, o art. 201, ao prever as diversas coberturas da previdência social brasileira, diz que elas serão reguladas na forma da lei.

Como, por exemplo, evitar que uma lei venha e diminua o desejo constitucional de proteção à maternidade (inciso II) ou aos dependentes, por meio das pensões (inciso $\mathrm{V}$ )?

Assim, v.g., uma lei que admitisse o salário-maternidade para todas as mães, com exclusão daquelas que têm filhos adulterinos, poderia ser tida como efetivadora do desejo constitucional de proteção à maternidade? Obviamente que não, já que a lei teria introduzido clara diminuição ao conceito de maternidade (afinal, há menos maternidade no caso da mãe que tem um filho fora do casamento?).

Da mesma forma, a Constituição prevê que o benefício deverá preservar o seu valor real, na forma da lei $\left(\operatorname{art.} 201, \S 4^{\circ}\right.$ ). Ora, se a lei não viabiliza a preservação do valor real, poderá ser tida como implementadora do desejo

I1. "Que a nossa Constituição de 1988 é Constituição dirigente. isso é inquestionável. O conjunto de diretrizes, programas e fins que enuncia, a serem pelo Estado e pela sociedade realizados, a ela confere o plano global normativo, do Estado e da sociedade. O seu art. 170 prospera, evidencialmente, no sentido de implantar uma nova ordem econômica" (GRAU, Eros Roberto. A ordem econômica na Constituição de 1988. (8a. cdição) São Paulo: Ed. Malheiros, 2003. p. 153). 
constitucional? Se restar demonstrado que esta lei claramente inviabiliza a preservação do valor de compra do benefício, não há como ser respaldada. ${ }^{12}$

Assim, esta lei representaria um redutor na eficácia do dispositivo da Constituição, conspirando contra a sua força normativa. ${ }^{13}$

Se isto se dá com uma norma que diminui os efeitos da Constituição. pior ainda serão a situações em que a ausência de norma pudesse reduzir a sua efícácia a zero quando o famoso "nos termos da lei" nunca foi implementado ou ficar a esperar a atuação do legislador infraconstitucional por anos e anos. Aqui, a eficácia zcro conduz a total ausência da força normativa do comando constitucional - que passa a ser mero aconselhamento ou orientação, jamais implementados. Nestes casos, há que se observar o seguinte: todos os agentes do dircito, uma vez decorrido algum lapso sem que o programa constitucional tenha sido implementado, devem se orientar para extrair da disposição constitucional toda a sua força. Assim, advogados devem peticionar, a sociedade deve se mobilizar por intermédio de suas entidades associativas, o Ministério Público deve exigir e o Judiciário deve comandar segundo a intenção constitucional.

Poder-se-ia objetar dizendo que somente o controle de constitucionalidade por omissão seria utilizável no caso presente. No entanto, como os instrumentais tendentes a este controle também tiveram a sua força normativa

12. Aliás, perceba-se que a Constituição prevê a preservação do valor real a partir dos critérios indicados em lei e não em atos administrativos. Atualmente, o art. 4 I da Lei de Benefícios, no seu "caput", menciona que o reajustamento se dará com base em percentual definido em regulamento. Aqui. somentc seria admissível a interpretação de que a Lei estabeleceu os critérios e apenas o percentual ficou por conta do ato administrativo, se o ato administrativo efetivamente preservar e demonstrar que preservou os parâmetros legais - o que, em geral, não vem ocorrendo.

13. Para KONRAD HESSE a força normativa da constituição, se revela no fato de representação muito mais do que decorre de uma mera equação momentânea de poder. possuindo. "ainda que de forma limitada, uma força própria, motivadora e ordenadora da vida do Estado" (A força normativa da Constituição. Porto Alegre: Sérgio Tabris Editor, 1991. p.l1). Havendo uma reciproca incidencia da Constituição na vida real e dos fatos da realidade no mundo da Constituição, a força normativa da Constituição consolida o meio termo, fazendo com que se evite o abandono da normatividade constitucional em nome do domínio das situações fäticas c também que se evite que a mera normativismo da Constituição se faça despido de qualquer relação com a realidade. Assim, em sintese "a força normativa da Constituição não reside, tão-somente. na adaptação inteligente a uma dada realidade. A Constituição juridica logra converter-se, ela mesma, $\mathrm{cm}$ força ativa, que se assenta na natureza singular do presente (individuelle beshaffenheit der Gegenwart). Embora a Constituição não possa, por si só, realizar nada, ela pode impor tarefas. A Constituição transforma-se em força ativa se essas tarefas forem efetivamente realizadas. se existir disposição de orientar a própria conduta segundo a ordem nela establecida. de a despeito de todos os questionamentos e reservas provinientes dos juizos de conveniència, se puder identificar a vontade de concretizar essa ordem" (Idem. p. 19). 
bastante (senão quase totalmente) subtraída. não há como se inviabilizar que a disposição constitucional tenha a sua eficácia extraída da interpretação diária dada por todos que operam em tudas as instâncias do direito. Assim, o ideal seria a implementação da política desejada de forma ordenada pela legislação e pela Administração Pública. Não há que se esperar eternamente que um comando constitucional seja implementado, contando apenas com a vontade política. Aqui, dissentimos dos que entendem que o recurso ao Judiciário retira o elemento político que deve nortear a questão das políticas públicas. Primeiro, não entendemos que estamos - ainda que a questão seja apreciada em ação coletiva - diante de um política pública. Segundo, o Judiciário apenas fará a interpretação da Constituição segundo os valores que a norteiam e que devem ser considerados para fins de assegurar a força normativa da Constituição. Isto tudo não invalida o plano de ação política, nem politiza de forma espúria a atuação do Judiciário. ${ }^{14}$

Entendemos que, na verdade, a se considerar a existência de normas programáticas, elas devem ser revestidas, uma vez não cumprido os programas nelas inscritos, da possibilidade de investir o titular de um direito subjetivo à sua prestação. O primeiro destinatário da norma programática, assim. seria o legislador. O segundo seria o próprio cidadão, a quem se deve viabilizar todas as formas possiveis de sua implementação - quer no plano político, quer no plano juridico.

14. Aliás. são comuns os exemplos, especialmente em matéria de direito à saúde, de atuação do próprio Supremo Tribunal Federal conferindo, especialmente a partir da idéia de dignidadc humana, direitos a tratamentos de saúde ou a medicamentos. 
Aliás toda a norma que encerra um direito de natureza social tem como principal destinatário o próprio cidadão. ${ }^{15}$

IV. A interpretação constitucional e os direitos sociais

A questão anterior - e outras correlatas - pode facilmente scr resolvida na esfera da interpretação, como veremos a seguir.

Para dar força normativa à Constituição, o Juiz, especialmente $\mathrm{em}$ matéria de dircito social, deve fazer um esforço interpretativo a que os nossos juizes estão pouco habituados - deve, portanto, haver uma verdadeira revisão de conceitos c um reposicionamento do stałus conferido à interpretação dentro deste sistema. Senão vejamos.

A idéia que a interpretação da Constituição é de extrema relevância para a constante adequação do direito à realidade social não é de ninguém desconhecida.

A teoria do dircito constitucional, já se reconhece, tem um pouco de ciência da realidade e outro tanto de ciência normativa. Não se pode, no entanto, deixar que os elementos de ciência da realidade tomem conta por completo da interpretação constitucional, sob pena de o aspecto normativo ser relegado a segundo plano. Da mesma forma, para que a Constituição tenha força normativa não basta uma interpretação meramente literal. Na realidade, já dizia Konrad Hesse, a força normativa da Constituição decorre da confluência dos dois fatores (realidade/norma) que a informam.

15. Colhe aqui fazer com coro com JOSÉ LUIS BOLZAN DE MORAIS no sentido de que a retirada desta qualidade em relação direitos sociais (isto é, geração de direitos subjetivos), "aponta para uma fragilização eficacial destas normas de novo tipo. próprias do constitucionalismo contemporâneo. dizendo-as dependentes de uma ação legislativa posterior que lhes complete o sentido e permita. assim. a usufruição dos conteúdos nela expressos. Como, de regra, a legislaçào infraconstitucional não era adotada. via-se o cidadão frustrado em suas expectativas, servido tal atitude não apunas para impedir o acesso aos conteúdos constitucionais. mas, também, para fragilizar, na prática, o valor atribuido ao pacto constituinte do Estado. Mesmo que tratemos diversamente os vários conteúdos constitucionais. cremos que esses novos direitos incorporam, para além de uma eficácia paralisante de atitudes com elas incompativeis, verdadeira pretensão a ser satisfeita pela autoridade pública inconstitucionalizando a sua atitude omissiva, além de permitir que o interessado demanda a satisfação do conteúdo proposto/prometido em sede constituciunal, sob pena de contribuir-se para o desgaste de legitimação suportado pelo constitucionalismo contemporâneo e ofender de morte a base estruturante do Estado Democrático de Direito" (Direitos humanos "globais (universais)" de todos, em todos os lugares. In Direitos humanos, globalização econômica e integração regional - desafios do direito constitucional internacional. PJOVESAN, Flávia (coordenadora). São Paulo: Ed. Max Limonad, 2002, p. 526). 
Nunca é demais, neste ponto, lembrar as lições de Eros Grau, ${ }^{16}$ segundo as quais a interpretação constitucional necessariamente deve-se dar sob a perspectiva da evolução histórica (uma leitura processual da interpretação da Constituição).

Aqui vale lembrar, com Francesco Ferrara, que "a lci, porím, não se identifica com a letra da lei. Esta é apenas um meio de comunicação: as palavras são símbolos e portadores de pensamento, mas podem ser defeituosas. Só nos sistemas jurídicos primitivos a letra da lei era decisiva, tendo um valor místico e sacramental. Pelo contrário, com o desenvolvimento da civilização, esta concepção é abandonada e procura-se a intenção legislativa. Relevante é o elemento espiritual, a voluntas legis, embora deduzida atravís das palavras do legislador. Entender uma lei, portanto, não é somente aferrar de modo mecânico o sentido aparente e imediato que resulta da conexão verbal; é indagar com profundeza o pensamento legislativo, descer da superfície verbal ao conceito intimo que o texto encerra e desenvolvê-lo em todas as direções possiveis: scire leges non hoc. A missão do intérprete é justamente descobrir o conteúdo real da norma juridica, determinar em toda a plenitude o seu valor, penetrar o mais que é possivel (como diz Windscheid). Só assim a lei realiza toda a sua força de expansão e representa na vida social uma verdadeira força normativa.",17

Ora, se esta observação foi feita pelo o autor para a interpretação das leis em geral, ela ganha maior expressão quando se trata da interpretação constitucional, onde a expressão da vontade politica, que deve resguardar o pacto originalmente ali estabelecido, integra, como elemento componente, o próprio método de interpretação. A análise conformadora com a realidade social faz parte indissociável da interpretação constitucional e, afirmamos, com expressão mais relevante do que em qualquer outro ramo do direito.

16. Confira-se o texto A interpretação constitucional como processo. Brasilia: Editora Consulex, 1998.

17. Veja-se a obra Interpretação e aplicação das leis. 4a. edição. Arménio Amado: Coimbra. 1987, p. 128. Mais adiante este mesmo autor lembrar que "a finalidade da interpretaçáo é determinar o sentido objectivo da lei, a vis ac potestas legis. A lei é expressão da vontade do Estado e, tal vontade persiste de modo autónomo, destacada do complexo dos pinsamentos e das tendências que animaram as pessoas que contribuiram para a sua emanação. O intérprete deve apurar o conteúdo de vontade que alcanção expressão em forma constitucional, e não já as voliçoes alhures manifestadas ou que não chegaram a sair do campo intencional. Pois que a lei não é o que legislador quis nu quis exprimir, mas tão somente aquilo que ele exprimiu na forma de lei" (p. 134). 
Aqui, deve-se ter em mente que a interpretação constitucional é essencialmente uma interpretação de princípios (embora, na nossa Constituição, encontremos também algumas regras, esta afirmação não deve ser afastada).

Aqui, chamamos a atenção para as distinções feitas por Inocêncio Mártires $^{18}$ que parte basicamente da idéia de que os princípios enunciam programas, encontrando-se a serviço da unidade política (especialmente quando dispostos constitucionalmente). Não se submetem, pois, à regra do "tudo ou nada" Portanto, para que se obtenha esta unidade politica, faz-se indispensável que os princípios se acomodem e cedam lugar uns aos outros quando analisados na situação concreta. Somente o princípio da dignidade humana teria um "status" diferenciado: "Porque se trata de um método de ponderação de bens no caso concreto, é intuitivo que, sob esse prisma, não exista uma hierarquia fixa, abstrata e apriorística, entre os diversos valores constitucionais, ressalvado, é claro, o valor da dignidade humana, porque a pessoa é o valor-fonte de todos os valores ou o valor fundante da experiência ética" 19

Ainda aqui devem ser analisadas as colocações de EROS GRAU, segundo as quais "um sistema supõe ordenação e unidade (ordenação interior e unidade de sentido). No direito, dominado pelos sentidos axiológico e teleológico, a idéia de ordenação conduz à de adequação: tanto o legislador como o juiz devem tomar adequadamente os dados, axiológicos, do direito (Canaris 1989/18). Daí cuidar-se, no caso do direito, de adequação valorativa. Podemos definir sistema jurídico (cada sistema jurídico) como uma ordem teleológica de princípios gerais de direito (Canaris, 1989/77). Não se trata, note-se bem, de ordem de normas, conceitos, institutos, valores ou axiomas, mas de ordem princípios gerais. A conexão aglutinadora das normas que compõem o sistema jurídico - dai a sua unidade encontra-se nos princípios gerais do direito (de cada dircito). Mas é necessário sabermos, não obstante, que os principios como veremos adiante - também são normas. As normas compreendem um gênero do qual são espécies, as regras e os princípios" 20 80 a 83.

18. Confiras-se a obra Interpretação constitucional. Porto Alcgre : Sérgio Fabris Editor, 1997. p 19. Idem, p. 84.

20. "O direito posto e o direito pressuposto". 2. ed. São Paulo: Ed. Malheiros. 1998, p. 19. 
A partir desta perspectiva, resta claro que a interpretação, no plano constitucional, é evolutiva ${ }^{21}$ e tem como perspectiva a adequação dos desideratos acordados constitucionalmente a uma visão histórica e política contemporânea. Assim, diríamos que houve um pacto em 1988, mas este pacto tem que ser constantemente renovado e, para tanto, os valores ali expostos devem ser adequados à realidade do dia-a-dia. Não há como se considerar uma modificação do que foi inicialmente acordado - já que para tanto haveria que existir atuação do poder constituinte originário -, mas um reposicionamento, segundo os conceitos atuais. dos valores inicialmente dispostos.

Assim, por exemplo, a nossa Constituição consagrou o valor social do trabalho. sendo que este deve ser redimensionado sempre a partir da perspectiva atual. Neste contexto, entendemos, com Inocêncio Mártires, que a dignidade humana esteja, atualmente, a respaldar as soluções referentes aos diversos embates entre os princípios. Esta, no entanto, deve ter a mensuração dimensionada partindo-se do principio da democracia (art. 1o. da Constituição Federal). ${ }^{2}$ Portanto, todos os demais princípios, quando analisados em conflito aparente de normas constitucionais, devem ser avaliados a partir da perspectiva de que, a sua

21. Aqui devem ser rememoradas as seguintes lições: "Sem que se opere algum tipo de ruptura na ordem constituida como um movimento revolucionário ou a convocação do poder constituinte originário -, duas são as possibilidades de mutação ou transição constitucional: (a) através de uma reforma do texto, pelo exercicio do poder constituinte derivado, ou (b) através do recurso aos meio interpretativos. A interpretação evolutiva é um processo informal de reforma do texto da Constituição. Consiste na atribuição de novos conteúdos à norma constitucional. sem modificação de seu teor literal, em razão de mudanças históricas ou de fatores politicos e sociais que não estavam presentes na mente dos constituintes" (I uis Roberto Barroso. Interpretação e aplicação da Constituição. São Paulo: Saraiva, 1996, p. 137).

22. A respeito vejam-se as lições de KARL LAREN7 (Metodologia da ciência do direito. (3. ed.) Fundação Calouste Gulbenkian : Lisboa. 1997), para quem há ainda um conflito entre uma jurisprudência de interesses que vem sendo suplantada pela jurisprudência de valores. Menciona ainda os valores supralegais e o "ethos juridico dominante" (pp. 163-182). E, citando BYDLINSKI, preleciona que: "Não é suficiente, segundo ele, a alusão às concepções valorativas comummente reconhecidas ou mesmo preponderantes na comunidade juridica. Ao invés, carecem estas de uma "seleção mediante categorias jurídicas" Tais critérios vê-os ele nos princípios jurídicos, que também aqui neste livro são considerados como directrizess, que operam a mediação entre a idéia de Direito (ou os valores juridicos de escalão superior) e as regulações de Direito positivo. A seleç̧ão necessária de valores sociais, comum ou dominantemente reconhecidos, a partir da sua 'relevância juridica'. decorreria 'mediante a sua comprovação ascendente'. o comprovar-se se na sua substância se podem representar como concretização da idéia de Direito em relação à sociedade historicamente dada. e em sentidu "descendente" se forem reconheciveis como idéias directrizes de regulações juridico-positivas" (pp. 177-178). 
implementação, considera, ainda que forma subjacente, os princípios da dignidade humana e da democracia. O cotejo entre princípios constitucionais se resolve em favor daquele que atualmente, na situação concreta, potencializar a dignidade humana e a democracia. Este foi, segundo se percebe do próprio art. lo. da Constituição e dos demais dispositivos que a informam, os princípios aos quais os demais vieram se conformando.

Estas observações são fundamentais quando estamos tratando de direitos sociais, já que, na composição da dignidade humana e da democracia devem ser considerados estratégicos.

Portanto, em cotejo de princípios. us referentes aos direitos sociais assumem destaque pela sua posição inicial já bastante aproximada dos princípios da dignidade e da democracia. Assim, haveria princípios (como os referentes aos direitos sociais), que possuiriam posição de destaque, no cotejo inicial, pela sua natural proximidade em relação aos postulados democráticos e de dignidade da pessoa humana. Não se quer. com isto, dizer que, no caso concreto, não possam ceder a sua vez a um outro princípio. mas isto só ocorrerá em situações em que realmente ficar demonstrado que tal postura potencialize a dignidade humana e o ideal democrático. Não se está aqui a falar de direitos naturais, mas em princípius, cuja acomodação no tempo. representem uma maior dimensão dos valores relacionados à dignidade humana è à democracia (que sequer poderiam, se ainda fosse tutalmente aceita esta categoria, se aproximar do conceito dos direitos naturais).

Perceba-se que valores como dignidade humana e democracia devem ser dimensionados segundo o seu momento histórico na perspectiva de interpretação processual do direito constitucional. Alcançado a cada dia um grau maior de democracia, por exemplo. maior será a abrangência de seu conteúdo. A democracia recém inaugurada na realidade brasileira de 1988 não é a mesma democracia de mais de 15 anos após a edição da Constituição. Na verdade, o maior grau de maturidade na democracia representa uma necessária acomodação deste conceito à realidade dos nossos dias. O mesmo se daria com a dignidade humana.

Assim. sempre retomaríamos aos valores acordados originariamente, para detectá-los. No entanto, os valores ali apostos devem se acomodar à nossa atual condição social, sob pena de uma Constituição não refletir o que foi acordado pela sociedade em que se insere. 
É claro que. para os direitos sociais, estas lições são indispensáveis, já que a acomodação de sua interpretação é muito importante. No entanto, ainda aqui, deve-se ter presente com Konrad Hesse que "não é, portanto, em tempos tranqüilos e felizes que a Constituição normativa vê-se submetida à sua prova de força. Em verdade, esta prova dá-se nas situações de emergência, nos tempos de necessidade. Em determinada medida, reside aqui a relativa verdade da conhecida tese de Carl Schmitt segundo a qual o estado de necessidade configura ponto essencial para a caracterização da força normativa da Constituição. Importante, todavia, não é verificar, exatamente durante o estado de necessidade, a superioridade dos fatos sobre o significado secundário do elemento normativo, mas, sim, constatar, nesse momento, a superioridade da norma sobre as circunstâncias fáticas (...) A Constituição não está desvinculada da realidade histórica concreta do seu tempo. Todavia, ela não está condicionada, simplesmente, por essa realidade. Em cada eventual conflito, a Constituição não deve ser considerada, necessariamente. a parte mais fraca" 23

Portanto, ainda que haja necessidade de acomodação dos valores inicialmente dispostos à realidade, não há como se desejar que a Constituição seja revista sempre, no ato de interpretação e mesmo de atuação de poder constituinte (ainda que derivado), para modificá-la pelo sabor contingencial de fatos econômicos. Aliás, pensar de forma diversa implica a consagração da perda da própria força normativa da Constituição. Em matéria de direitos sociais - em especial os trabalhistas e os previdenciários isto fica bem nítido. Não é qualquer difículdade orçamentária ou econômica que deve representar a diminuição dos direitos sociais, sob pena de se enfraquecer os princípios da dignidade humana e da democracia. Aliás, indo mais além, temos defendido em diversas oportunidades, uma superação desta idéia no quc enunciamos como direito adquirido social.

À luz destas considerações, inclusive, seriam justificáveis todas as ponderações realizadas anteriormente a respeito da inviabilidade de interpretações constitucionais restritivas dos dircitos sociais. Assim, parece-nos justificável, por exemplo, que a interpretação constitucional é indispensável na consolidação subjacente de uma teoria dos direitos sociais enquanto direitos fundamentais da pessoa humana. A técnica de interpretação evolutiva da Constituição assume efetiva 
relevância quando são mencionados os direitos sociais inscritos no texto constitucional. Assim, se há necessidade de constante reafirmação do pacto constitucional firmado originariamente, este excrcicio é ainda mais intenso quando se fala em direitos sociais, em vista da própria mobilidade das contingências sóciojurídicas que os envolvem. A dinâmica e prática dos direitos sociais está a confirmar a nccessidade de que estes sejam reafirmados sempre dentro da parte do direito constitucional que í ciência normativa, sem se esquecer, no entanto, daquele cadinho de ciência da realidade. Inobstante, ainda aqui c acima de tudo aqui, não há como se viabilizar que incertezas econômicas e financeiras alterem o pacto originariamente firmado de defesa dos direitos sociais - caso contrário, jamais será possível a consolidação de uma teoria e prática dos direitos fundamentais da pessoa humana.

\section{Conclusão}

Diante de tudo quanto exposto, há que se concluir dizendo que apenas uma análise dos direitos sociais a partir da hermenêutica constitucional será capaz de sua consolidação. Assim, não há que rebaixar os direitos suciais do art. $6^{\circ} \mathrm{da}$ Constituição Federal a uma construção de legalidade inferior baseada, por exemplo e no caso dos direitos previdenciários, na mera utilização de Portarias, Instruções Normativas ou Ordens de Serviço. Somente na teoria da constituição será possivel reconstruir e consolidar uma verdadeira teoria dos direitos sociais enquanto direitos fundamentais. Fora disto, apenas há espaço para uma depreciação da quantidade e, mais, da qualidade dos direitos sociais. O território da Constituição deve ser o verdadeiro espaço de consolidação de uma hermenêutica de fortalecimento de direitos como os da previdência social, os referentes à saúde, ao direito do trabalho, etc.. E, por outro lado, sem a consolidação dos direitos sociais, e de uma metodologia constitucional de sua compreensão. não há espaço - especialmente cm paises pobres como o Brasil - para o fortalecimento dos direitos humanos.

São Paulo, dezembro de 2004. 